\title{
Infecçáo crônica por Toxoplasma gondii induzindo hipertrofia de neurônios do plexo mientérico do cólon descendente de Rattus norvegicus
}

\author{
Chronic infection due to Toxoplasma gondii inducing neuron hypertrophy \\ of the myenteric plexus of Rattus norvegicus descending colon
}

\author{
Janaína Soares ${ }^{1}$; Neide M. Moreira ${ }^{2}$; Aristeu V. da Silva ${ }^{3}$; Débora de M. G. Sant Ana $^{3}$; Eduardo José de A. Araújo ${ }^{3 *}$ \\ ${ }^{1}$ Enfermeira pela Universidade Paranaense - UNIPAR e Discente do Mestrado em Enfermagem, Universidade de São Paulo - USP \\ ${ }^{2}$ Discente do Mestrado em Ciências da Saúde, Universidade Estadual de Maringá - UEM \\ ${ }^{3}$ Docente do Mestrado em Ciência Animal, Universidade Paranaense - UNIPAR
}

Recebido em 8 de Dezembro de 2008

Aceito em 16 de Fevereiro de 2009

\section{Resumo}

Neste estudo, foram avaliados os efeitos da infecção crônica por taquizoítos de Toxoplasma gondii sobre os neurônios mientéricos do cólon descendente de ratos adultos. Utilizaram-se 10 ratos Wistar machos, com 60 dias de idade, divididos em grupo controle e experimental, que foram inoculados por via oral com $10^{5}$ taquizoítos do genótipo I de T. gondii. Após 30 dias, os animais foram anestesiados e submetidos à laparatomia. $\mathrm{O}$ cólon descendente foi retirado, mensurado, dissecado e seus preparados de membrana submetidos à técnica de Giemsa, para coloração dos neurônios do plexo mientérico, seguido por análise morfométrica e quantitativa. Verificou-se que a infecção não causou alteraçôes nas dimensóes do órgão ou na população neuronal, porém houve um aumento significativo da área do pericário e citoplasma.

Palavras-chave: Toxoplasmose, taquizoítos, neurônios entéricos.

\begin{abstract}
The effects of the chronic infection due to Toxoplasma gondii tachyzoites on the myenteric neurons of the adult rat descending colon were assessed in this study. Ten male, 60-day-old, Wistar rats, divided into control and experimental group were orally inoculated with $10^{5}$ tachyzoites from Toxoplasma gondii genotype I strain. After 30 days, the animals were anesthetized and submitted to laparotomy. The descending colon was removed, dissected, and the whole-mounts were staining by Giemsa, in order to observe neurons of the myenteric plexus, followed by quantitative and morphometric analysis. It was verified that the infection caused alterations neither with respect to the dimensions of the organ nor the neuronal population; however, there was a significant increase of the perikarion area and the cytoplasm.
\end{abstract}

Keywords: Toxoplasmosis, tachyzoites, enteric neurons.

A toxoplasmose atinge diversas espécies animais, inclusive o ser humano, sendo geralmente assintomática em imunocompetentes (DUBEY, 1998). Em imunocomprometidos, pode causar cegueira, desordens neurológicas, hepatite e pneumonia (ASCENZI et al., 2005). Há uma grande prevalência da encefalite toxoplásmica (REY, 2001), reflexo da afinidade primária do Toxoplasma gondii pelo sistema nervoso central (SMART et al., 1990).

Em cães, os principais sinais clínicos da infecção pelo T. gondii são febre, anorexia, diarréia e pneumonia. Em pequenos ruminantes leva ao aborto e outros transtornos reprodutivos (URQUHART et al., 1990; LIMA et al., 2008). A diarréia é

*Autor para correspondência: Eduardo José de A. Araújo

Laboratório de Pesquisa em Neurogastroenterologia Experimental,

Universidade Paranaense - UNIPAR, Praça Mascarenhas de Moraes, 4282,

CEP 87502-210 Umuarama - PR, Brasil; e-mail: eduardoaraujo@unipar.br

Trabalho de Conclusão de Curso em Enfermagem da autora Janaína Soares um achado comum em suínos (DUBEY et al., 1979) e aves (GALLI, 2008), e alteraçóes do sistema nervoso são descritas em cães e felinos (URQUHART et al.,1990). O mecanismo indutor da diarréia em animais infectados é ainda desconhecido e uma possível explicação é que o $T$. gondii altera o funcionamento do Sistema Nervoso Entérico (SNE), responsável pela coordenação da motilidade intestinal (FURNESS, 2006), hipótese reforçada por sua afinidade pelo tecido nervoso (DUBEY, 1997).

A ausência de publicaçóes prévias na literatura científica, que avaliem a relação entre a infecção causada pelo $T$. gondii e os neurônios entéricos, fizeram este grupo de pesquisa iniciar recentemente essa linha de estudo. Esse estudo exploratório teve como objetivo avaliar os efeitos da infecção crônica, induzida por taquizoítos de uma cepa genótipo I de $T$. gondi, sobre os neurônios mientéricos do cólon descendente de ratos adultos. 
Todos os procedimentos experimentais realizados neste estudo foram previamente aprovados pelo Comitê de Ética em Pesquisa Envolvendo Experimentação Animal da Universidade Paranaense. Para tanto, foram utilizados 10 ratos (Rattus norvegicus) Wistar machos de 60 dias de idade (peso corporal 280,75 g $\pm 28,85$ ). Os animais foram divididos em dois grupos: grupo controle (GC, $\mathrm{n}=5)$ e grupo experimental (GE, $\mathrm{n}=5)$. Os animais do GC receberam solução salina por via oral e os do GE foram inoculados pela mesma via com $10^{5}$ taquizoítos de $T$. gondii da cepa brasileira BTU IV, isolada do cérebro de cão com sintomatologia neurológica e classificada como pertencente ao genótipo I pela análise do gene SAG 2 (DA SILVA et al., 2005). Os animais foram mantidos em caixas plásticas com grades individuais, num biotério com temperatura constante de $25^{\circ} \mathrm{C}$ e alternância de ciclos claro-escuro de 12 horas. Todos os animais receberam ração comercial para roedores (NUVITAL ${ }^{\oplus}$ ) e água ad libitum.

Trinta dias após a inoculação, os animais foram anestesiados por injeçáo intramuscular, segundo o seguinte protocolo descrito por Pachaly et al. (2003). Realizou-se a coleta de sangue pela punção do plexo retro-orbital de cada animal, visando detecçáo de anticorpos séricos anti-T. gondii por aglutinação direta (DA SILVA et al., 2002). Em seguida, os animais foram submetidos à eutanásia por administração intracardíaca de solução concentrada de cloreto de potássio $(\mathrm{KCl})$ após laparatomia. $\mathrm{O}$ cólon descendente foi retirado, mensurado em seu comprimento total e circunferência, para cálculo de área, e submetido à fixação em formol acético e dissecção, para a retirada da túnica mucosa e da tela submucosa, confeccionando-se os preparados totais. Os preparados totais foram corados pela técnica de Giemsa (BARBOSA, 1978), seguido de dissecação pela retirada da túnica mucosa e tela submucosa, confeccionando os preparados totais.

Os neurônios presentes em 120 campos microscópicos distribuídos homogeneamente em toda circunferência intestinal de todos os animais foram contados, com a utilização de microscópio óptico Motic BL com objetiva de $40 \times$. A área de cada campo microscópio foi de $0,21 \mathrm{~mm}^{2}$. Para a análise morfométrica, mensurou-se a área do pericário e do núcleo de 300 neurônios distribuídos homogeneamente em toda circunferência intestinal de cada espécime. A mensuração foi realizada com o auxílio de um microscópio óptico, com objetiva de $40 \times$, acoplado a sistema de análise de imagem: MOTIC Imagem $\times$ Plus versão 2.0. A partir da diferença entre essas áreas, calculou-se a área do citoplasma. Além disso, determinou-se a razão entre a área do núcleo e pericário de cada neurônio, no intuito de se averiguar a proporção ocupada por essa organela dentro do pericário.

Não foi observada letalidade para nenhum animal deste experimento e nem perda de peso ou alteraçóes na área do cólon descendente (Tabela 1). Esses resultados reforçam a informação de que o rato é um animal mais resistente que o camundongo à infecção por T. gondii (DUBEY, 1996; DUBEY; FRENKEL, 1998), o que permite ser utilizado como modelo experimental em infecçôes crônicas.

Nenhum dos ratos apresentou diarréia ou qualquer outra alteraçáo clínica durante o experimento, nem lesões macroscópicas ou mesoscópicas no cólon no decorrer da dissecção, o que sugere uma infecção subclínica. Diferente dos resultados deste trabalho, a inoculação de taquizoítos da cepa RH, também do genótipo I, em ratos por via intraperitonial levou à progressiva perda de pelos, alteraçáo no crescimento e redução do peso com o aumento da dose de parasito inoculada (DE CHAMPS et al., 1998). Possivelmente, o número de formas infectantes viáveis tenha sido pequeno, diante da capacidade do sistema imune do hospedeiro limitar sua disseminação. Ratos Wistar inoculados com taquizoítos do genótipo I, por via intraperitonial, sobreviveram com doses menores que $10^{7}$ (para adultos) e $10^{4}$ (para jovens) (DE MEUTER, 1972 apud DE CHAMPS et al., 1998; REMINGTON et al., 1958). Apesar da utilização, neste estudo, de uma suspensão de $10^{5}$ taquizoítos de uma cepa do genótipo I, a mesma não foi letal para nenhum rato, discordando dos autores citados acima, possivelmente por ter sido utilizada a via oral, já que a acidez gástrica pode reduzir a viabilidade das formas infectantes (MONTOYA; REMINGTON, 2000). Apesar de ter passado pelo suco gástrico, os taquizoítos induziram a uma infecção pelo T. gondii, detectada pela presença de anticorpos anti-Toxoplasma gondii. Por se tratar de um estudo exploratório inicial, não foi feito o reisolamento do parasito em camundongos.

Neste estudo, não houve redução na densidade neuronal ou na população total de neurônios entéricos do órgão (Tabela 2), apesar da utilização de uma cepa genótipo I, que possui maior virulência em camundongos e maior capacidade de atravessar barreiras biológicas (SAEIJ et al., 2005) do que as cepas genótipos II e III (BARRAGAN; SIBLEY, 2003). Cepas do genótipo I de T. gondii apresentam afinidade pelo tecido nervoso de ratos, conforme pode ser observado no estudo de De Champs et al. (1998), que isolou cistos teciduais do homogenato de cérebros de ratos infectados. Apesar da observação de cistos nos homogenatos, esses autores referem não ter sido possível sua visualização nas análises histológicas, atribuindo o fato à pequena quantidade de cistos teciduais, e concordam com resultados observados por Dubey (1996). Neste estudo, não foi possível visualizar formas do parasito no interior das células neuronais mientéricas, possivelmente porque, caso tenham se formado cistos, esses podem ter sido em pequena quantidade, não sendo detectados nas amostras realizadas. Contudo, para confirmação da possível existência de cistos teciduais no interior de neurônios entéricos, faz-se necessária a realização de estudos imunohistoquímicos com a marcação específica do parasito.

Neste estudo, os neurônios entéricos tiveram um aumento da área do pericário, causado pela ampliação do citoplasma (Tabela 3). Porém, mantiveram-se inalterados os demais parâmetros morfométricos avaliados, resultados semelhantes aos encontrados em estudos prévios com a infecção crônica com taquizoítos de T. gondii do genótipo III, que levou a um aumento da área do pericário, núcleo e citoplasma dos neurônios do cólon descendente (SUGAUARA et al., 2008). Infecçôes agudas causadas por cepa do genótipo II não induziram a alteraçôes morfométricas nos neurônios do cólon descendente de ratos, fato atribuído à ausência de tempo para causar uma resposta inflamatória proliferativa (SUGAUARA et al., 2009). Isso pode ser indicativo de que, no íleo, a infecção provocou uma grande redução da expressão gênica dos neurônios mientéricos, enquanto o oposto ocorreu no cólon descendente, cujos genes e o mecanismo de interação do parasito com a maquinaria celular dos neurônios mientéricos merecem ser investigados. 
Tabela 1. Média \pm desvio-padrão do peso corporal, comprimento, largura e área do cólon descendente de ratos controle (GC), submetidos à infecção por uma cepa genótipo I de Toxoplasma gondii (GE) durante 30 dias.

\begin{tabular}{ccccr}
\hline Grupos & Peso $(\mathbf{g})$ & Comprimento $(\mathbf{c m})$ & Largura $(\mathbf{c m})$ & Área $^{\left(\mathbf{c m}^{2}\right)}$ \\
\hline GC $(\mathrm{n}=5)$ & $368,3 \pm 16,8$ & $8,36 \pm 1,49$ & $1,00 \pm 0,19$ & $8,26 \pm 1,58$ \\
GE $(\mathrm{n}=5)$ & $338,4 \pm 26,5$ & $9,42 \pm 2,42$ & $1,12 \pm 0,04$ & $10,55 \pm 2,67$ \\
\hline
\end{tabular}

Valores apresentados como média \pm desvio-padrão. Grupos comparados pelo Teste $t$ para amostras independentes.

Tabela 2. Média \pm desvio-padrão do número de neurônios em 25,2 mm² (120 campos microscópicos) e projeção deste número para o cólon descendente de ratos controle (GC), submetidos à infecção por uma cepa genótipo I de T. gondii (GE) durante 30 dias.

\begin{tabular}{ccc}
\hline Grupos & Densidade neuronal em 25,2 $\mathbf{~ m m}^{\mathbf{2}}$ & Projeçáo do número de neurônios para todo o cólon descendente \\
\hline GC $(\mathrm{n}=5)$ & $4.163,8 \pm 336,38$ & $137.109,17 \pm 32.497,90$ \\
$\mathrm{GE}(\mathrm{n}=5)$ & $4.538,2 \pm 852,09$ & $187.071,59 \pm 41.684,69$ \\
\hline
\end{tabular}

Valores apresentados como média \pm desvio-padrão. Grupos comparados pelo Teste $t$ para amostras independentes.

Tabela 3. Mediana (percentil 25; 75) da área do pericário, do núcleo, do citoplasma e a razão núcleo/corpo de neurônios mientéricos corados com azul de metileno do colón descendente de ratos controle (GC), submetidos à infecção por uma cepa genótipo I de Toxoplasma gondii (GE) durante 30 dias.

\begin{tabular}{ccccc}
\hline Grupo & Área do pericário $\left(\boldsymbol{\mu \mathbf { m } ^ { 2 } )}\right.$ & Área do núcleo $\left(\boldsymbol{\mu} \mathbf{m}^{2}\right)$ & Área do citoplasma $\left(\boldsymbol{\mu} \mathbf{m}^{2}\right)$ & Razáo núcleo/pericário \\
\hline GC $(\mathrm{n}=5)$ & $120,16^{*}(74,20 ; 183,00)$ & $60,48(38,08 ; 86,06)$ & $55,82^{*}(34,93 ; 93,85)$ & $0,49(0,41 ; 0,57)$ \\
$\mathrm{GE}(\mathrm{n}=5)$ & $126,28^{*}(86,57 ; 177,43)$ & $62,71(42,44 ; 84,45)$ & $59,45^{*}(39,46 ; 93,85)$ & $0,49(0,40 ; 0,58)$ \\
\hline
\end{tabular}

Valores seguidos de asterisco numa mesma coluna apresentam diferença significativa (Teste de Mann-Whitney, $\mathrm{p}<0,05$ ).

Possivelmente, as alteraçóes plásticas dos neurônios entéricos sejam respostas desses órgãos ao processo inflamatório provocado pela infecção, assim como ocorrido em experimentos de cirurgia experimental no cólon de ratos (FONTES et al., 2004). Na distribuição de frequência dos neurônios mientéricos em classes, de acordo com a área do pericário e a razão entre a área do núcleo e do pericário, a infecção não levou a alteraçóes na frequência de neurônios nessas diferentes classes. A manutenção da frequência de neurônios na mesma classe difere dos achados experimentais em que $T$. gondii demonstrou possuir maior potencial de crescimento em neurônios grandes (HALONEN; LYMAN; CHIU, 1996).

A infecção por uma cepa do genótipo I de $T$. gondii, durante 30 dias, não resultou em nenhuma alteração numérica na população neuronal e nas dimensôes do cólon descendente, porém acarretou a hipertrofia da área do pericário e do citoplasma de neurônios mientéricos de ratos.

\section{Referências}

ASCENZI, P.; BOCEDI, A.; GRADONI, L. Do neuroglobin and myoglobin protect Toxoplasma gondii from nitrosative stress? IUBMB Life, v. 57, n. 10, p. 689-691, 2005.

BARBOSA, A. J. A. Técnica histológica para gânglios nervosos intramurais em preparados espessos. Revista Brasileira de Pesquisas Médicas e Biológicas, v. 11, n. 2-3, p. 95-97, 1978.

BARRAGAN, A.; SIBLEY, L. D. Migration of Toxoplasma gondii across biological barriers. Trends in Microbiology, v. 11, n. 9, p. 426-430, 2003.

Da SILVA, A. V.; CUTOLO, A. A.; LANGONI, H. Comparação da reação de imunofluorescência indireta e do método de aglutinação direta na detecção de anticorpos anti-Toxoplasma em soros de ovinos, caprinos, caninos, e felinos. Arquivos do Instituto Biológico, v. 69, n. 1, p. 7-11, 2002.

Da SILVA, A. V. et al. Genotyping of Toxoplasma gondii strains isolated from dogs with neurologicas signs. Veterinary Parasitology, v. 127, n. 1 , p. $23-27,2005$

De CHAMPS, C. et al. Toxoplasma gondii infection in rats by the RH strain: inoculum and age effects. Parasite, v. 5, n. 3, p. 215-218, 1998.

DUBEY, J. P. et al. Porcine Toxoplasmosis in Indiana. Javma, v. 15, n. 6, p. 604-608, 1979.

DUBEY, J. P. Pathogenicity and infectivity of Toxoplasma gondii oocysts for rats. The Journal of Parasitoloy, v. 80, n. 6, p. 951-956, 1996.

DUBEY, J. P. Distribution of tissue cysts in organs of rats fed Toxoplasma gondii oocysts. The Journal of Parasitoloy, v. 83, n. 4, p. 755-757, 1997.

DUBEY, J. P. Comparative infectivity of Toxoplasma gondii bradyzoites in rats and mice. The Journal of Parasitology, v. 84, n. 6, p. 1279-1282, 1998.

DUBEY, J. P.; FRENKEL, J. K. Toxoplasmosis of rats: a review, with considerations of their value as an animal model and their possible role in epidemiology. Veterinary Parasitology, v. 77, n. 1, p. 1-32, 1998.

FONTES, R. B. V. et al. The Myenteric plexus of the rat colon after fecal stream diversion: a morpho-quantitative study. Autonomic Neuroscience: Basic \& Clinical, v. 114, n. 1-2, p. 39-46, 2004.

FURNESS, J. B. The enteric nervous system. Malden: Blackwell Publishing, 2006.

GALLI, S. Toxoplasmose natural e experimental em galinhas. 2008. 55 p. Dissertação (Mestrado em Ciência Animal) - Universidade Paranaense, Umuarama. 
HALONEN, S. K.; LYMAN, W. D.; CHIU, F. C. Growth and development of Toxoplasma gondii in human neurons and astrocytes. Journal of Neuropathology and Experimental Neurology, v. 55, n. 11, p. 1150-1156, 1996.

SAEIJ, J. P. J.; BOYLE, J. P.; BOOTHROYD, J. C. Differences among the three major strains of Toxoplasma gondii and their specific interactions with the infected host. Trends in Parasitology, v. 21, n. 10, p. 476-481, 2005.

LIMA, J. T. R. et al. Prevalência de anticorpos anti-Toxoplasma gondii e anti-Neospora caninum em rebanhos caprinos do município de Mossoró, Rio Grande do Norte. Brazilian Journal of Veterinary Research and Animal Science, v. 45, n. 2, p. 81-86, 2008.

MONTOYA, J. G.; REMINGTON, J. S. Toxoplasma gondii. In: MANDEL, G. L.; BENNETT, J. E.; DOLIN, R. (Eds.). Principles and pratice of infections diseases. $5 \mathrm{ed}$. Churchill Philadelphia: Livingstone, 2000. p. 2858-2885.

PACHALY, J. R. et al. Anesthesia of wistar rats (Rattus novergicus) with allometrically scaled doses of ketamine, xylazine, acepromazine and atropine- preliminary report. Arquivos de Ciências Veterinárias e Zoologia da UNIPAR, v. 6, n. 1, p. 195, 2003.

REMINGTON, J. S. et al. Studies on chronic toxoplasmosis: the relation of infective dose to residual infection and to the possibility of congenital transmission. American Journal of Ophthalmology, v. 46, n. 5, p. 261-267, 1958.

REY, L. Parasitologia: parasitos e doenças parasitárias do homem nas Américas e na África. 3 ed. Rio de Janeiro: Guanabara Koogan, 2001. 856 p.

SMART, E. P. et al. Toxoplasmosis of the stomach: a cause of antral narrowing. Radiology, v. 174, n. 2, p. 369-370, 1990.

SUGAUARA, E. Y. Y. et al. Alterations of the myenteric plexus of the ileum and the descending colon caused by Toxoplasma gondii (genotype III). Arquivos de Neuro-Psiquiatria, v. 66, n. 3, p. 516-523, 2008.

SUGAUARA, E. Y. Y. et al. Hypertrophy of the neurons in the ileum from rats infected with cysts of Toxoplasma gondii (Genotype II). Acta Scientiarum, v. 31, n. 2, 2009. In press.

URQUHART, G. M. Parasitologia Veterinária. Rio de Janeiro: Guanabara Koogan, 1990. 247-250 p. 